\title{
The potential role of dentists in HIV screening
}

\author{
A. J. Santella, ${ }^{* 1}$ D. I. Conway ${ }^{2}$ and R. G. Watt ${ }^{3}$
}

IN BRIEF

- Suggests rapid HIV screening represents an opportunity for the dentist to expand their role in diagnosis and prevention.

- Highlights that additional training, logistical and financial support may be needed to enable dentists and other members of the dental team to fulfil this role.

- Proposes further research is needed to explore whether UK patients are prepared to accept HIV screening from the dentist.

Recent evidence suggests there is a role for the dental team, particularly dentists, in offering chairside HIV screening to patients during dental appointments. HIV is no longer a death sentence with early diagnosis and effective treatment contributing to a good prognosis. Despite the availability of both venipuncture diagnostic and rapid saliva/finger prick screening tests for HIV infection, 25\% of people living with HIV in the United Kingdom are undiagnosed and remain at risk of transmitting their infection if having unprotected sex. This paper highlights the international evidence that supports dentists' willingness to conduct HIV screening and dental patient acceptance, and explores whether this is an opportunity or a step too far.

\section{INTRODUCTION}

Tuesday, 1 December 2015 was World AIDS Day - a time for us all to reflect on the action still needed to combat the human immunodeficiency virus (HIV) epidemic. It has been over 30 years since the first cases of HIV were diagnosed. The United Nations (UN) estimates that globally 36.9 million people are now living with HIV. In 2014, over two million individuals became newly infected and 1.2 million people died from acquired immune deficiency syndrome (AIDS) related illnesses. Rates of HIV infection vary considerably around the world with 95\% of infections occurring in developing countries. ${ }^{1}$

However, despite the magnitude of this global public health problem there are signs of optimism. Across the world 15 million people living with HIV are now accessing antiretroviral therapy (ART). Encouragingly, 73\% of pregnant women living with HIV had access to ART to prevent mother-tochild transmission and this has resulted in a $58 \%$ reduction in new HIV infections from 2000-2014. New rates of HIV infection have fallen by $35 \%$ across the world since 2000 and there has been a $42 \%$ reduction in

'Hofstra University, Department of Health Professions, Hempstead, New York, USA; ${ }^{2}$ University of Glasgow, Dental School, Glasgow, Scotland; ${ }^{3}$ University College London, Department of Epidemiology and Public Health, London, England

*Correspondence to: Dr. Anthony J. Santella

Email: Anthony.Santella@hofstra.edu

\section{Refereed Paper}

Accepted 27 January 2016

DOI: 10.1038/sj.bdj.2016.171

@British Dental Journal 2016; 220: 229-233
AIDS-related deaths since the peak in $2004 .^{1}$

An HIV diagnosis is now no longer an automatic death sentence. Developments in ART and care have dramatically improved the prognosis of a person diagnosed with HIV infection. Most people diagnosed with HIV infection can now expect to live a long and healthy life. Indeed, HIV infection is now considered a long-term condition, similar in many respects to other chronic conditions such as diabetes. Recent guidelines from the World Health Organisation set a 'treat all' recommendation, removing all limitations on eligibility for ART among people living with HIV - all populations and age groups are now eligible for treatment. ${ }^{2}$

The other key element in HIV prevention strategies is improving the availability and access to HIV screening. Early diagnosis dramatically improves health outcomes of the individuals infected and is an important means of reducing future infections. There have been major improvements in HIV screening and testing technology which now makes accurate test results much easier and quicker. In the United Kingdom (UK) HIV screening is now offered in a wide range of settings including antenatal services, sexual health clinics, general practitioners (GP) practices and pharmacies, and self-testing kits are available from the internet and in pharmacies.

The aims of this paper are to review developments in HIV prevention and treatment and to discuss dentists' potential to become more involved in offering HIV screening. First we will summarise UK HIV data and highlight evidence underpinning current preventive strategies to combat this infectious condition. Details of HIV diagnostics available in the UK will then be presented. Studies from across the world assessing dentists' and dental patients' willingness and attitudes towards HIV screening will also be summarised. Finally, we will consider opportunities for UK dentists to offer HIV screening and the barriers to this agenda being taken forward.

\section{EPIDEMIOLOGY OF HIV IN THE UK}

In 2013 there was an estimated 107,800 (95\% confidence interval 101,600-115,800) people living with HIV in the UK. Around 25\% of those are undiagnosed and remain at risk of transmitting their infection if having unprotected sex. It is estimated that 90\% of HIV infections are contracted through unsafe sexual contact. The overall prevalence was 2.8 per 1,000 population aged 15-59 years, with a $2: 1$ male to female ratio ( 1.9 per 1,000 women and 3.7 per 1,000 men). ${ }^{3}$

Incidence trends are shown in Figure 1. There were 6,000 people $(4,480$ men and 1,520 women) newly diagnosed with HIV in the UK in 2013, slightly down from 6,250 diagnoses in the previous year. These case numbers equate to an estimated new HIV diagnosis rate of approximately 1.0 per 10,000 population (1.4 per 10,000 men and 0.46 per 10,000 women). New diagnoses have been declining since they peaked in 2005 (at 7,890), largely due to a decrease in the number of diagnoses reported among heterosexuals born in high HIV prevalence countries (particularly sub-Saharan Africa). ${ }^{3}$ 
There are wide inequalities in the burden of HIV. In 2013, the prevalence of HIV was around 30 times higher among men who have sex with men and among Black-African men and women compared to the general population in the UK. ${ }^{4}$ Approximately 75\% of HIV infections in the UK are among these two groups. However, HIV prevalence is also highest in the most deprived communities despite similar proportions of those being offered and accepting HIV screening tests being similar in different socioeconomic groups/areas of socioeconomic deprivation. Health inequalities also manifest in late diagnosis particularly among older people and those from black and minority ethnic groups - the latter partly explained by the high proportion acquiring the infection abroad. $^{3}$

\section{HIV PREVENTION STRATEGIES}

HIV is no longer the death sentence associated with the UK's 1980s tombstone advertising campaign. ${ }^{5}$ People living with HIV have near normal life expectancy and better clinical outcomes if they are diagnosed early. Early diagnosis also leads to earlier access to effective treatment and reduces the risk of onward transmission. A meta-analysis of published studies showed that people who know their HIV status reduce their high-risk sexual behaviours by $68 \%{ }^{6}$

On World AIDS Day 2014 the UN Joint Programme on HIV/AIDS (UNAIDS) launched its 'Fast-Track' strategy which aims to end the world AIDS epidemic by 2020. In it they set out the ' $90-90-90$ approach by 2020' with targets of: $90 \%$ of people living with HIV knowing their HIV status; 90\% of people who know their HIV-positive status on treatment; and $90 \%$ of people on treatment with suppressed viral loads.

The UK has adopted the 'Fast-Track' strategy and UK HIV preventive policies aim to reduce the number of HIV transmissions via increasing prevention, increasing early diagnosis and improving the treatment and care of those living with the virus. ${ }^{7,8}$ The only routine HIV screening testing that takes place out with sexual health services is antenatal screening for pregnant women. There are efforts to expand screening to other healthcare settings including: GPs, hospitals, and pharmacies, however, thus far dental practices have not really been considered.

In addition to saving lives, early detection of HIV has considerable potential cost savings. Public Health England estimated lifetime treatment costs to the NHS associated with HIV infection of £280,000 to £360,000, and estimated that if all the newly diagnosed cases in 2010 had been prevented, £1.0 to $£ 1.3$ billion lifetime NHS treatment (not

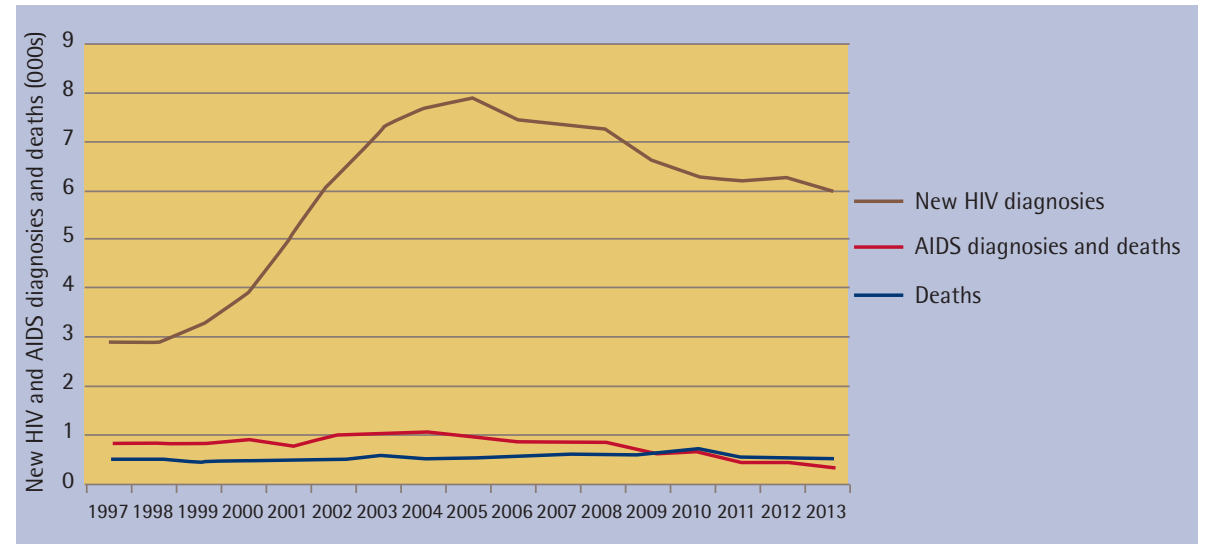

Fig. 1 Annual new HIV and AIDS diagnoses and deaths in UK (1997-2013) (graph created using data reported in 'HIV in the United Kingdom 2014 Report: data to end 2013'3)

including wider societal costs) would have been saved..$^{9}$ Moreover, HIV care costs are substantially more if patients are diagnosed late. ${ }^{10}$

\section{OVERVIEW OF HIV DIAGNOSTICS}

Rapid HIV screening works by seizing either antibodies or antigen on a surface and then attaching molecules to them that are made visible for individuals or clinicians to see. This process occurs in approximately 20 minutes. All rapid screening tests have what is known as a window period. A window period is the time during which infection is undetectable. Most, recent fourth generation rapid tests have a window period of one month. When test results are read, they can be found to be reactive (that is, preliminary positive) or negative. All reactive test results should be followed by a confirmatory test. A confirmatory test is also known as a Western blot test and detects HIV antibodies in the blood sample. There are nine rapid HIV tests available in the UK. All manufacturers report sensitivity (true positive rate) and specificity (true negative rate) above 99\% (see Table 1 for approved HIV tests in the UK). ${ }^{11}$ The first

\begin{tabular}{l|l}
\hline \multicolumn{2}{l}{ Table 1 Available rapid HIV tests in England" } \\
\hline Test name & Manufacturer \\
\hline OraQuick Advance HIV1/2 & OraSure \\
\hline Determine HIV 1/2 & Alere \\
\hline Determine HIV 1/2 Ag/Ab Combo & Alere \\
\hline INSTI HIV-1/HIV-2 Rapid Antibody Test & Pasante/BioLytical Laboratories \\
\hline Core HIV 1\&t2 & Core Diagnostics \\
\hline Immunoflow HIV1-HIV 2 & Core Diagnostics \\
\hline Vikia HIV 1/2 & bioMerieux \\
\hline Rapidan anti-HIV1/2 & Turklab \\
\hline HIV Self Test & BioSURE \\
\hline
\end{tabular}

HIV self-test kit (Biosure, www.hivselftest. co.uk) went on sale in the UK in April 2014. The Biosure test claims to be $99.7 \%$ accurate if used as instructed.

\section{INTERNATIONAL STUDIES ON THE ROLE OF DENTAL PROFESSIONALS IN HIV SCREENING}

To date, there have been few studies on dentists' attitudes toward HIV testing in the dental setting, and none of these studies were conducted in the UK. Although most were cross-sectional surveys, one was mixed methods and included a qualitative component (focus groups). A summary of these six studies can be found in Table 2 . Willingness to offer rapid HIV screening varied (Australia: 61.5\%, United States: 56.7\%, Vietnam: 90\%). Dentist attitudes as to whether rapid HIV screening is needed in the oral health setting also varied (China: $91.2 \%$, India: 79.9\%, Korea: 88\%). Finally, the biggest barriers for implementing rapid HIV screening in the oral health setting included: lack of education for oral health provider on test (Australia, China, Korea), lack of knowledge of how to administer the test (India, 
Vietnam), and subjective norms of patients and colleagues (United States). ${ }^{12-17}$

Further comparison of additional more detailed data from the US and Australia are provided below. Among the 532 Australian dentists surveyed, most (78.1\%) were uncomfortable advising a patient of a reactive screening result. Additionally, those who thought rapid HIV screening was needed in the dental setting were younger $(\mathrm{P}=0.0008)$, had fewer years of experience $(\mathrm{P}=0.002)$, worked in a private health fund run clinic $(\mathrm{P}=0.04)$, treated few people living with HIV in the past year $(\mathrm{P}=0.04)$ and had a lower HIV knowledge score $(\mathrm{P}=0.004)$. More than half (51.1\%) of participants preferred salivabased testing, as opposed to blood (9.6\%). Almost half (45.9\%) felt that HIV testing was necessary before invasive procedures, but $37.8 \%$ did not think it was necessary at all. The majority of participants (88.7\%) felt that only dentists should conduct rapid HIV screening, compared to oral health therapists and hygienists (18.6\%) and dental nurses (13.3\%). Before screening could be implemented in the oral health setting, participants felt that their lack of education relating to HIV screening (44.8\%) and not being comfortable reporting a reactive test result (35\%) needed to be addressed..$^{15}$

Among the 1,802 American dentists surveyed about their willingness to provide expanded HIV screening in oral health settings, only 14 offered rapid HIV screening. Clinical knowledge and previous training in HIV disease were not associated with their willingness to offer rapid HIV screening; however, they were associated with acceptance of the screening as part of the dentists' professional role. Additionally, dentists who believed rapid HIV screening was of public health significance were more likely to report willingness to conduct it. Finally, willingness to offer rapid HIV screening and accept it as a professional duty was correlated with agreement that patients would accept screening in the oral health setting and both colleagues' and patients' perceptions of them would improve. ${ }^{13}$

Few studies have examined patient attitudes of receiving rapid HIV screening in the oral health setting. Of 150 dental patients from Kansas City, U.S., 73\% reported willingness to take a free HIV screening during their dental visit. Patients with a history of multiple prior screening tests for HIV were more likely to agree to oral rapid HIV screening in the dental clinic.18 In another study of 470 dental patients in New Jersey, U.S. (288 university dental clinic patients and 182 private dental clinic patients) examining attitudes toward chairside medical screenings, 80\% and 55\% of respondents, respectively, were in favour of being screened for HIV during a dental visit. ${ }^{19}$ Several patient studies have been conducted in New York City (NYC), one of the HIV epicentres. In a public hospital demonstration project $97.6 \%$ of dental patients who were approached agreed to be tested. ${ }^{20}$ In another study at a NYC-based dental school that examined patients' agreement to participate in oral rapid HIV screening, only $8.2 \%$ of the patients contacted by the clinic administration staff completed testing. However, when approached by a faculty member or dental student during the dental visit admission and tested during the dental visit, $88.2 \%$ completed testing. ${ }^{21}$ In a similar study of 436 patients across three university-based dental hygiene clinics, over half $(72.2 \%)$ indicated acceptability to HIV screening in a dental hygiene clinic, with 85.3\% choosing oral RHT. Over 30\% indicated that they were willing to receive the RHT at no cost. ${ }^{22}$ In another survey of 521 patients attending private and public dental clinics in Sydney, Australia, 82\% were willing to have a rapid HIV screening in the oral health setting, $76.1 \%$ preferred the oral screening, and $74.9 \%$ were not willing to pay for the test. ${ }^{23}$ In a dental patient study in India, acceptance of HIV screening in the dental setting was high $(71.0 \%$ clinic and 70.5\% private). ${ }^{24}$ Finally, screening implementation issues have not gone unnoticed. In a qualitative study of 19 dental patients, a number of logistical issues related to implementation of oral rapid HIV screening were found and included: getting positive test results; need for professional counselling and linkage to care for HIV positive patients; providing HIV prevention educational materials; and the need for privacy. ${ }^{25}$

\section{HIV SCREENING IN DENTAL SET- TINGS - AN OPPORTUNITY OR A STEP TOO FAR?}

Significant progress has been made in tackling the HIV epidemic in the UK. However, much still needs to be done as there are over 100,000 people living with HIV and rates of new infections remain stubbornly high. Dramatic advances in treatment have radically changed the nature of this disease. Now a central plank of HIV prevention national policy is for people to be tested early for the infection and to begin ART as soon as possible. In this article we have presented an update on developments in HIV and raise the question of whether dentists in the UK should be offering rapid HIV screening. Some may think this is well beyond the role of UK dentists, whereas others may see an opportunity ahead.

As is the case with other areas of prevention such as smoking cessation and alcohol advice, there is strong justification for dentists to extend their clinical preventive role to other relevant areas. A significant

Table 2 Major studies of dentists' attitudes toward HIV screening in the oral health setting

\begin{tabular}{|c|c|c|c|c|c|}
\hline Country & Sample size & Study design & $\begin{array}{l}\text { Willing to offer } \\
\text { HIV screening } \\
(\%)\end{array}$ & $\begin{array}{l}\text { Believe rapid } \\
\text { HIV screening is } \\
\text { needed in dental } \\
\text { clinic (\%) }\end{array}$ & $\begin{array}{l}\text { Biggest barrier for HIV screening } \\
\text { implementation }\end{array}$ \\
\hline Australia & 532 & National, cross-sectional survey & 65.1 & $N / A^{*}$ & $\begin{array}{l}\text { Lack of education for oral health } \\
\text { provider on test }\end{array}$ \\
\hline China & 477 & Regional (Xi'an), cross-sectional survey & NA & 91.2 & $\begin{array}{l}\text { Lack of education for oral health } \\
\text { provider on test }\end{array}$ \\
\hline India & 503 & $\begin{array}{l}\text { National, cross-sectional survey in } 4 \text { cities (Delhi, } \\
\text { Gandhinagar, Bhubaneswar, and Hyderabad) }\end{array}$ & NA & 79.9 & $\begin{array}{l}\text { Lack of knowledge of how to admin- } \\
\text { ister test }\end{array}$ \\
\hline Korea & 475 & National, cross-sectional survey & NA & 88 & $\begin{array}{l}\text { Lack of education for oral health } \\
\text { provider on test }\end{array}$ \\
\hline United States & 1802 & National, representative, cross-sectional survey & 56.7 & N/A & $\begin{array}{l}\text { Subjective norms of patients and } \\
\text { colleagues }\end{array}$ \\
\hline Vietnam & 42 & $\begin{array}{l}4 \text { focus groups with brief survey in Hanoi and Ho } \\
\text { Chi Minh City }\end{array}$ & 90 & Yes & $\begin{array}{l}\text { Lack of knowledge of how to admin- } \\
\text { ister test }\end{array}$ \\
\hline
\end{tabular}


proportion of the UK population are regularly seen by dentists - nearly 30 million adults (56\% of the population) were seen by a dentist in the last 24 months. ${ }^{26}$ Dental staff are uniquely placed to provide preventive support as they regularly reach parts of the population that other NHS services cannot. This is particularly true for young and middle-aged adults who may have limited contact with primary medical care but who are still at a stage of life where interventions to change behaviours will have an impact. Dentists are highly trained professional health care workers and have the training and experience to present difficult news to patients and ensure appropriate treatment or referral, for example, a case of urgent referral for suspected oral cancer. Undertaking HIV screening tests in dental practices could be considered a safe healthcare environment where ongoing referral to relevant services could be secured, while self-testing at home could be more isolated and unsupported, and while there may be greater reluctance to attend sexual health clinics. The oral (saliva) HIV screening test is very much in keeping with the practice of dentistry and, therefore, may seem of direct relevance to patients. Dentists were previously at the forefront of the early detection of HIV/AIDS, particularly with the prominence of oral conditions including candida, oral hairy leukoplakia, and Kaposi sarcoma. ${ }^{27}$ This potential new role in HIV screening may therefore be appropriate.

However, a range of barriers need addressing before this becomes a reality. Lack of training and knowledge, limited time and concerns over costs (including the questions: who would pay for it? Would patients pay for it?), perceived relevance of HIV testing to dentistry, concerns over upsetting or alienating patients, and fears over the sensitivity of discussing sexual health matters are all major barriers that need to be overcome. In addition, special contractual arrangements may need to be administered for this issue to be adopted in busy NHS practices, and monitoring of equity of access and uptake of screening in dental settings. Some of these same issues - particularly in relation to the sensitive topic - were raised and overcome during the Human Papilloma Virus (HPV) Oral Prevalence Study in Scotland (HOPSCOTCH) feasibility study. ${ }^{28}$

People living with HIV often experience stigma and discrimination based upon fear and ignorance. Many people living with HIV also face prejudice related to their sexuality and/or ethnicity. If dentists are to become involved in offering HIV screening, patients would need to have complete confidence in the confidentiality and respect they will receive from their dental providers. Staff training would therefore be essential for all members of the dental team. At present no research has been published on the attitudes and knowledge of dental staff in this area. Therefore, research is needed to explore how dental professionals and teams, as well as dental patients, would view the prospect of dentists offering HIV screening. This information would help design tailored training courses for dental staff.

Moreover, if dental practices became involved in this area, it would be essential to have local protocols in place and information available on sexual health services to refer patients for definitive testing, support and ongoing care as required. Dentists and their teams would also need to be able to access relevant support and advice from experts in HIV.

It is highly unlikely that dentists would offer universal HIV screening to all their patients. A targeted approach would seem more appropriate, but the logistics of how this would be offered requires some thought to avoid prejudicial practices. One option would be to inform all adult patients that the practice offers HIV screening, and then for the patients to request more information about the testing procedures. Or alternatively, as Public Health England propose for commissioning HIV screening in general (dental practices are not thus far considered), to potentially focus/commission HIV screening services in dental practices working in areas or communities with known higher diagnosed prevalence (at least 2.0 per 1,000 population). ${ }^{29,30}$

\section{CONCLUSIONS}

At the emergence of the HIV/AIDS epidemic in the 1980s, dentists were at the forefront of early detection screening for oral lesions associated with HIV infection and AIDS. ${ }^{31}$

Three decades on, great progress has been made in diagnosis, treatment and prognosis. Dentists and other members of the dental team may still have a role in helping to identify new cases of HIV with the goal of improving health outcomes, addressing health inequalities, and improving the quality and quantity of life. ${ }^{32}$ A quarter of those infected with HIV do not know they have it, and are therefore not in treatment and remain at risk of transmitting the infection. There is a global and UK call to normalise and expand the provision of routine HIV screening and testing. In the United States they are further ahead with this agenda, exemplified by the 'know your status' preventive campaign (http://www.knowyourstatustoday.com/). In our view, dentists can have a potential role in normalising and delivering HIV screening - and in working towards ending the HIV epidemic.

1. United Nations. UNAIDS 2014. Information available online at http://www.unaids.org/en/resources/ documents/2014/ (accessed September 2015).

2. World Health Organization. Guideline on when to start antiretroviral therapy and on pre-exposure prophylaxis for HIV. Geneva: WHO, 2015. Available online at http://www.who.int/hiv/pub/guidelines/ earlyrelease-arv/en/ (accessed October 2015).

3. Yin Z, Brown A E, Hughes $G$ et al. HIV in the United Kingdom 2014 Report: data to end 2013. London: Public Health England, 2014.

4. Fakoya I, Reynolds R, Caswell G, Shiripinda I. Barriers to HIV testing for migrant black Africans in Western Europe. HIV Med 2008; 9 (Suppl. 2): 23-25.

5. HM Government. AIDS Don't Die of Ignorance [YouTube]. 1986. Available online at https://www. youtube.com/watch?v=9SqRNUU0k7s (accessed September 2015).

6. Marks G, Crepaz N, Senterfitt J W, Janssen R S. Meta-analysis of high-risk sexual behaviour in persons aware and unaware they are infected with HIV in the United States. JAIDS 2005; 39: 446-453.

7. Westrop S J, McNeal F, Anderson J, Gill N, Nardone A. HIV Testing and Self-Testing. London: Public Health England, 2014.

8. Scottish Government. Sexual Health and Blood Borne Virus Framework. Scotland: Healthier Scotland, 2011. Available online at http://www.gov. scot/Publications/2011/08/24085708/0 (accessed September 2015)

9. Health Protection Agency. Evidence and resources to commission expanded HIV testing in priority medical services in high prevalence areas. Colindale, 2011. Available online at http://www.boltonshealth matters.org/sites/default/files/Evidence\%20to\%20 commission\%20expanded\%20HIV\%20testing.pdf (accessed October 2015).

10. National Institute of Clinical Excellence. Increasing the uptake of HIV testing among black Africans in England and increasing the uptake of HIV testing among men who have sex with men-Costing report - implementing NICE guidance. National Institute of Clinical Excellence, London, 2011. Available online at https://www.nice.org.uk/guidance/ph33 (accessed October 2015).

11. National AIDS Manual- AIDSMAP. HIV testing. Nam Publications 2015. Available online at http://www. aidsmap.com/HIV-testing/page/1320696/ (accessed September 2015).

12. Wang L, Santella A J, Huang R et al. Knowledge of HIV and willingness to conduct oral rapid HIV testing among dentists in Xi'an China. PLOS ONE 2015; 10: e0119274.

13. Pollack H A, Pereyra M, Parish C L et al. Dentists' willingness to provide expanded HIV screening in oral health care settings: Results from a nationally representative survey. Am J Public Health 2014; 104: 872-880.

14. Park J C, Choi S H, Kim Y T et al. Knowledge and attitudes of Korean dentists towards human immunodeficiency virus/acquired immune deficiency syndrome. J Periodontal Implant Sci 2011; 41: 3-9.

15. Santella A J, Schlub T E, Schifter M, Tolani M, Hillman $\mathrm{R} J$. Australian dentists' perspectives on rapid HIV testing (RHT). Aust Dent J 2015; doi: 10.1111/adj.12371.

16. Ngainte P C, Santella A J, Watt R G, Saxena S R, Vatsyayan $V$. Envisioning the role of Indian dentists in conducting rapid HIV testing for early detection of HIV. Int J Dev Res. In Press.

17. Santella A J, Nguyen T A, Schifter M, Hillman R J. Vietnamese dentists' attitudes and willingness to conduct saliva-based HIV testing. J Dent Res 2015; 94: 3907.

18. Dietz C, Ablah E, Reznik D, Robbins D. Patients' atti tudes about rapid oral HIV screening in an urban, free dental clinic. AIDS Patient Care STDS 2008; 22: 205-212.

19. Greenberg B L, Kantor M L, Jiang S S, Glick M. Patients' attitudes toward screening for medical conditions in a dental setting. J Public Health Dent 2012; 72: 28-35. 
20. Blackstock $O J$, King J R, Mason R D, Lee C C, Mannheimer S B. Evaluation of a rapid HIV testing initiative in an urban, hospital-based dental clinic. AIDS Patient Care STDS 2010; 24: 781-785.

21. Nassry D, Phelan J, Ghookasian M et al. Patient and provider acceptance of oral HIV screening in a dental school setting. J Dent Educ 2012; 76: 1150-1155

22. Furnari W, Davide $S$, Leuwaisee $P$, Cortell $M$, Santella A J, Krishnamachari B. Dental hygiene patients' willingness to undergo HIV testing. Paper presented at: The American Dental Hygiene Association Annual Meeting. Las Vegas, Nevada, 2014.

23. Santella A J, Schlub T E, Schifter M et al. Willingness of dental patients to undergo HIV testing in the dental setting. Paper presented at: The International AIDS Conference. Melbourne, Australia, 2014.

24. Sansare K, Raghav M, Kasbe A, et al. Indian patients' attitudes towards chairside screening in a dental setting for medical conditions. Int Dent J 2015; 65: 269-276.

25. VanDevanter N, Combellick J, Hutchinson M K Phelan J, Malamud D, Shelley D. A qualitative study of patients' attitudes toward HIV testing in the dental setting. Nurs Res Pract 2012; 2012: 1-6.

26. Health and Social Care Information Centre. Number of people seen by an NHS dentist nearing 30 million. Available online at http://www.hscic.gov.uk/article/4993/Number-of-people-seen-by-an-NHS-dentist-nearing-30-million (accessed September 2015).

27. Greenspan D, Greenspan J S, Schiodt M, Pindborg J J. AIDS and the mouth. Copenhagen: Munksgaard, 1990.

28. Conway D I, Bagg J, Clarkson J et al. Human Papilloma Virus (HPV) Oral Prevalence in Scotland - HOPSCOTCH: Feasibility study. Scotland: Scottish Government Health Directorates Chief Scientist Office, 2015. Available online at http://www.cso.
scot.nhs.uk/wp-content/uploads/CZH_4_917.pdf (accessed October 2015).

29. Public Health England. Commissioning HIV Testing Services. PHE, London October 2014. Available online at http://www.nat.org.uk/media/Files/Publications/ Nov 2013 Toolkit.pdf (accessed October 2015).

30. Public Health England. Addressing Late HIV Diagnosis through Screening and Testing: An Evidence Summary. PHE, London 2014. Available online at http://webarchive.nationalarchives.gov. uk/20140722091854/http://www.hpa.org.uk/webc/ HPAwebFile/HPAweb_C/1317141126407 (accessed October 2015).

31. Silverman S Jr, Migliorati C A, Lozada-Nur F, Greenspan D, Conant M A. Oral findings in people with or at high risk for AIDS: a study of 375 homosexual males. J Am Dent Assoc 1986; 112: 187-192.

32. Reznik D A. Screening for infectious diseases in the dental setting. Dent Clin North Am 2012; 56: 809-818. 